\title{
STRUCTURAL APPROACH TO DIALECTIC COGNITION
}

\author{
Nikolay E. Veraksa \\ Moscow City Teachers' Training University \\ Moscow
}

\begin{abstract}
The author views dialectic cognition as an integral and unique process, which is based on dialectical logic - the logic of operating opposites. The development of this logic takes place during the preschool years through transformation of contradictory situations. The transformation process is carried out by dialectical cognitive actions.
\end{abstract}

Keywords: dialectic cognition, dialectical structure, child thinking, contradictory situation, opposites,

It is commonly believed that logic isn't engaged in cognition but merely describes it. My main thesis claims the opposite - logic guides cognition. The grounds for this viewpoint on the problem of interrelations of logical and psychological in cognition were set within the activity approach. P.Ya. Galperin wrote: "Psychology neither studies cognition in itself nor its every possible type, but merely the process of subject's orientation within the intellectual, or cognitive, tasks. Psychology studies orientation within intellectual tasks in terms of ways in which the content of a task is disclosed to a subject and in which tools are used for such disclosure" (1976, p. 94). Within the context of this approach, the logical structures are viewed as tools in the process of cognitive activity. A.N. Leontiev wrote: "Everybody becomes a subject of cognition only by mastering language, notions, logic, all of them being products of social and historical development" $(1983$, p. 80). A.N. Leontiev pointed out that logic is not an external trait of cognitive activity. This approach makes possible an analysis of those features of thinking process that are determined by implementation of certain cognitive tools. Considering orientation as an extralogical element of cognition, P.Ya. Galperin described interrelations of psychological and structural-logical aspects of cognition in the following manner: "An observer views the process of solving a 
cognitive task in terms transforming the initial task information into its intended solution. However, this process in addition employs tools, including various laws (logic, mathematics, mechanics, physics etc.), rules and algorithms... Logical interrelations of objects are one of many cognitive tools, a very powerful, but not the one and only. It is not used on a regular basis, not in all instances and doesn't constitute the very process of cognition. Logical interrelations and operations involving them is one thing, and orientation to them is another thing" (Galperin \& Elkonin, 1967, p. 621).

There is no doubt that cognition extends further than its tools and it cannot be reduced exclusively to them. Yet this doesn't undermine their role in the process of cognition defined as the task solving. Acknowledgment of the fact that logical tools are subject to orientation leads to acknowledgement of dependence of cognition on characteristics of the tools employed in the process. Works of L.S. Vygotsky and V.V. Davydov can well illustrate this point. L.S. Vygotsky wrote: "In our explanations of the nature of the solution-oriented psychological process we must proceed from the end goal but should not restrict ourselves to one. The process cannot be explained in terms of its goal. The main problem of the process of rational activity rests upon the question of the tools applied to this or that mental operation or rational activity" (1982, p. 126). As can be drawn from this passage, L.S. Vygotsky considered cognitive tools to be substantial factors affecting the process of cognition. Furthermore, in his works V.V. Davydov pointed out that "Cognition in its entirety can not be separated from, let alone be opposed to, the logical thinking and general application of logic, because the thought moves through the content of things in logical forms only" (1972, p. 339). We can reasonably conclude on the basis of the foregoing that cognition is dependent on a type of logic that a person uses.

In philosophy there are two types of logic: the formal and the dialectic. The formal logic inquires into state of objects and their sameness in the process of cognition.

\section{Dialectic logic and dialectical actions}

In contrast to formal logic, dialectic logic allows description of object's transformation. Russian philosophers of the second half of the $20^{\text {th }}$ century believed that dialectic logic cannot be formalized. This stand- 
point hindered researches into dialectic cognition. Some authors (like E.V. Ilyenkov and V.I. Maltsev) tried to formalize dialectic logic through the search of formal dialectic structures independent of content. But ultimately they faced difficulties in describing dialectic forms. Since late 1980s this problem has been worked out by a team of scholar under my supervision (L.F. Bayanova, E.E. Krasheninnikov, I.B. Shiyan and others). We believe that dialectic cognition uses special logic forms or logic structures.

Gestalt psychologists were the first in psychological science to formalize the meaning of a structure. Before them it was not uncommon to regard content as a combination of elements. Max Wertheimer claimed that structure was defined by the rule which caused elements to form a whole. Therefore the first step in defining a structure of an object is to find an inner rule that forms it. Such a rule can be called "a principle, or an order, of object arrangement." To illustrate this point, let's have a look at a circle. A circle has a well-known shape and some would say that this shape is a circle's structure. But let's now ask ourselves: what is the rule that forms a circle? The rule is that every point of the circumference is at the same distance from the other point called the center. It is clear that this rule or a principle of equal distance is the search for a structure that constitutes the circle and cannot be deduced out of properties of a point as an element of a line.

Therefore, a structure is a principle that controls formation of content and regulates all its elements. And a minimal element of content that reproduces its principle is called an element of a structure. A structure and an element of structure are invariants of content. Search for invariants that adequately describe a principle seems to be the main difficulty in describing a structure. Invariants are inherent in a structure but can be distinguished in certain content. They "convert" a structure into content and vice versa - content into the studied phenomena.

I believe that the invariants that describe a dialectic structure of any content are interrelations of the opposites. These are basic, fundamental and therefore indivisible elements of content.

The opposites possess two main properties:

1. There are always two of them, and presence of one always implies the existence of the other.

2. The opposites are mutually exclusive. 
Any object can be viewed from two different positions, both of which are correct and productive for solving different tasks. The first position analyzes object as an element of a whole. For example, "There are 22 players in a soccer match" - in this description mutually exclusive relations are absent. Moreover, it shows unity of content elements: 22 players are needed to start a game. This position represents formal logic approach. Dialectic position, on the other hand, is characterized by establishment of mutually exclusive relations or relations of the opposites. In this case, mutually exclusive relations appear as soon as we arrange players into two teams, for their goals are exactly opposite.

Our second thesis is that interrelations of the opposites can be described with different rules that define dialectic actions representing a course of possible cognitive transformations of the opposites. We discern several dialectic actions: the transformation, the seriation, the integration, the mediation. Let's mark opposites with A and B symbols and keep in mind that they are mutually exclusive.

Imagine that we are watching how object A transforms into object $B$. This process follows certain rule is called dialectic transformation that can be schematically represented as follows:

$$
\mathbf{A} \longrightarrow \mathbf{B}
$$

The aim of this action is to define the object's opposite and establish their correspondence. The example is finding the answer to the question "What is the opposite of life?" The common answer "death" is a result of dialectic transformation. Through this simple illustration we'd like to draw attention to the discrete nature of this action, meaning that it only defines the opposing extremes without the awareness of the conversional process itself.

The second dialectic action is seriation. It introduces a temporary variable into a process of conversion which becomes gradual transition (seriation) of one opposite to another. For example, night and day are two extremes that keep on converting from one to another through an intermediate state that is called morning. Therefore it would be correct to speak of transition of night into day rather than of their transformation from one to another. In contrast with the action of transformation, the seriation implicates awareness of the conversional process itself. At this we set the naturally occurring conversion apart from its cognitive realization which represents the dialectic action of seriation. Once again, 
the characteristic feature of the seriation is the presence of consciously acknowledged intermediate state, or a temporary variable, which enables the transition between the opposites. At this such a variable must necessarily comprise the properties of both opposing entities. If we mark two entities as $A$ and $B$, where $A$ is the opposite of $B$, and $A B$ is the intermediate state that comprises properties of both entities, the seriation could be schematically represented as follows:

\section{$\mathrm{A} \longrightarrow \mathrm{AB} \longrightarrow \mathrm{B}$}

The third dialectic action is integration, which is recognition of the opposites within an entity, foremost the mutually exclusive tendencies. A universal rule underlying this action is expressed by the principle that an entity is a unity of two mutually exclusive opposites in their interrelation. The example is a word as a psychological entity, because it is essentially a sign that is a unity of the objective (surface of a sign) and the ideal (meaning of a sign). The integration can be schematically represented as follows:

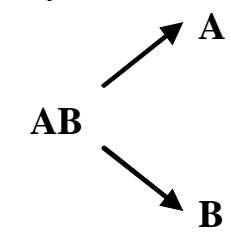

The fourth dialectic action is mediation. It is a search for a possible entity in which the opposites could co-exist in a unity. This action is also ruled by the principle that an entity is a unity of two mutually exclusive opposites in their interrelation. The mediation can be illustrated by a search for an object that would embody both mutually exclusive opposites "alive" and "not alive" thus representing, or mediating, their unity. One of the possible objects that satisfy this criterion is a virus that is considered "alive" because of its ability to reproduce, and at the same time complies with definition of "not being alive" on account of its ability to crystallize. The dialectic action of mediation is schematically represented as follows:

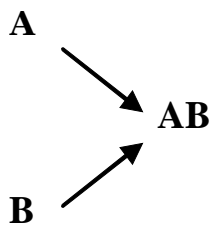


Two types of logic - formal and dialectic - were mentioned, both of which can be applied to problem solving. If so, in which cases dialectic cognition is used? Dialectic cognition is used in situations where mutually exclusive relations exist, and we call such situations contradictory.

\section{Use of dialectic cognition by preschoolers}

Observations show that preschool children begin to encounter with contradictory situations at a relatively early age. To prove this, we have worked out a simple method. A child was asked to play with a familiar push toy - a butterfly on wheels which wings flapped when its wheels turned. However, in that experiment movement of the wings was restricted with a rubber band to immobilize its wheels. By doing so we took an object with a clear-cut image familiar to a child (butterfly's wings flap and its wheels turn) and created an obstacle by turning it into a still object (the wings do not flap and the wheels do not turn).

According to a type of their actions, we distinguished three groups of children.

The first group didn't notice any alterations in toy's operation and acted their usual - moved the toy across the floor paying no attention to its still wings and wheels.

The second one did not notice that the toy was difficult to play with. They looked surprised and seemed to be confused by saying "doesn't move." However, they couldn't find the cause of the problem.

The children of the third group noticed immobility of the toy. Children pointed their fingers to a rubber band and one child also said "It stops it."

The results of this experiment show that around the age of two a child is able to:

- Tell the difference between two states of an object;

- Shift mentally from an actual image of an object (immobile object) to a previously formed one (mobile object);

- Find a cause that altered properties of an object.

What we observe is the action of transformation - a child replaced an actual image of the object with not simply any other, but with an exactly opposite image. The children's words "doesn't move" proves that they were expecting an opposite - the toy should have moved. 
Apart from contradictory situations, other instances could also determine development of dialectic cognition. In their early years children master various sequential actions taught by adults. These cyclic ordered actions determined by a social custom ritualize children's behavior. The example of such ordered actions a child takes part in is a daily routine of going out for a walk. The sequence in this case is first getting dressed (underwear - clothes - shoes - outer garments), then opening the door, closing it, etc. The studies show that preschoolers are highly sensitive to any alterations of the established routines. Changes in usual order of leaving a house or pressing the elevator button can cause an early age preschooler to react highly negatively demanding to restore the skipped step or the violated order. This emphasizes that preschoolers have established notions of sequences. Acquisition of these notions leads to acquisition of the corresponding universal dialectic schemes. For example, putting socks on before shoes reflects the dialectic action of seriation "bare foot - sock - shoe" that implies the action of enclosing "shoe - sock - bare foot." Moreover, the state when both shoes and socks are put on is common for both going outside and returning back home, and it therefore unites these two contexts in a dialectic action of mediation. And finally, mutually exclusive interrelations of two opposites "being outside" and "being at home" are prerequisite to the dialectic action of transformation. Therefore, by mastering these dialectic schemes presented by the real-life opposites a child prepares grounds for the respective dialectic cognitive transformations.

We have done several research projects on development of dialectic cognition in the preschool age (Veraksa, 1981). In an experiment called "A box with a weight" a child was presented with a hollow rightangled parallelepiped (children referred to it as a "brick"). A freely moving weight was inside the brick. Inclining the brick to one side caused moving of the weight inside it and thus changed its centre of gravity. The experimenter didn't tell children that there was anything inside the brick, which was presented to a child at a distance of one meter. The experimenter then placed the brick on a table top with its longer part hanging over the edge. At this the weight inside the brick was unnoticeably moved so the brick wouldn't fall off the table. While still holding the brick with his hand, the experimenter asked a child a question "What will become to a brick when I let go of it? Will it fall off the table or not?" 
Subsequent actions of the experimenter depended on children's answers. As a rule, children would say that it would fall. In this case the conductor would take his hand of the brick and it would fall. Then the experimenter would take the brick in his hands and ask "What would happen to a brick if I place it on this table again like the last time? Will it fall of the table or not?" If the answer was "It won't fall," the experimenter would then shift the brick's centre of gravity making it fall after taking his hand from it. The task was to constantly make a child wrong in his or her predictions regarding the brick. The experiment ended if children's answers stopped to change.

Let us see how this experiment works. It is known that preschoolers have a representative interpretation of reality. The situation that we offered to children here has its hidden properties, not obvious to children. These properties set two possible outcomes - either an object falls or it doesn't. Contradiction is administered into the situation by the technique of presentation an object: a child's predictions were made always wrong.

Children of different ages (from 3 years to 6 years old) took part in this experiment. A total number of children were 124; all of them were attending preschool educational institutions.

At the first presentation of the brick the children either remained silent or said "will fall," "will brake," "will fall into pieces." At second presentation, if the brick didn't fall the children's response usually was "won't fall." After the children had been offered both situations when the brick fell and when it did not, several types of answers were registered:

1. Persistent answer. Before each presentation a child gives the same answer "will" or "won't" fall.

2. Cyclic answer. The child answers "will fall," for example, and then quickly changes his or her answer to the opposite one "won't fall" and so on. It looks as if a child is unsure about his or her final answer.

3. Combined answer. A child says that he or she doesn't know whether the brick will fall or won't fall, because it "falls and doesn't fall."

4. Explanatory answer. A child gives different explanations of the bricks' properties, including the correct ones. 
During the experiment, age-specific differences in answers were discovered. It was common among 3-year-old preschoolers to look at the brick in silence. They also refrained from answering moderator's questions. All they could do was simply to state whether the brick fell or didn't fall down.

We have found the most interesting things in actions of 4-year-olds. During the initial 3-4 presentations they were giving persistent answers. They tried to base their predictions upon their notions of the object's properties. However, these notions showed to be unstable and easily repressed. These preschoolers were facing difficulties retaining two different notions of the same object. Near $64 \%$ of 4 -year-olds resorted to a cyclic answer - they hesitated and couldn't think up their final answer for some time. These actions, in our opinion, fundamentally differ from persistent answers.

Hesitation of the children indicates that in their representation of reality they reflect two possibilities concerning the brick's state. In other words, the children reflected the same brick as the one that fell and the one that didn't. These different notions of the same object didn't repress each other, but became equally active. A new complicated representational image had emerged which included two contradictory properties of the same object. And predictions of the children started to rely on this new image. However, this kind of image prevents from making predictions - as soon as a child answers "will fall," he or she discovers partiality of this answer because now the image includes the other state of the object - "won't fall." For this reason in order to sustain the integrity of the image, a child is forced not to decide on either of the options and continually shift from one answer to another. This type of answers also indicates that the children were put in a contradictory situation, for the object within their representational image had mutually exclusive properties. This image reflected external properties of the object and therefore the children couldn't give the right answer. To do so, the children had to change the image and change their ideas of the object.

Changing one's ideas of an object begins with realization of the discrepancy between an image of an object and one's predictions. This realization is evident in the third type of answers - combined answers. By means of the latter the preschoolers claimed the presence of contradictory properties of the brick "falls and does not fall." We call this cognitive action "the integration" of mutually exclusive properties, not multiplica- 
tion. When explaining this answer the children were saying "If I tell you that it will fall - it won't and if I tell you it won't - it will."

This is evidence of their understanding that their image of the brick doesn't match the situation. Therefore, the children face a problem of whether to abandon further efforts or to change their ideas of the object. This brings about a dialectic task of explaining why the object possesses mutually exclusive properties. Bringing about such a task changes the course of children's thinking. Their cognition becomes purposeful and directed towards finding a solution. The children have to mediate these opposites with a concept explaining their mutual active presence.

Note that it's the child, who poses a dialectic task of mediation; an experimenter doesn't ask him or her to explain the brick's properties. The task is simply to answer whether the brick will or will not fall off the table. This constitutes the method behind the experiment.

There are two common options at solving dialectic tasks. A child can either refuse to solve it - and this is the universal way of solving all contradictions, or he or she can try to build a new model of an object.

Some children did refuse to give an answer, but $9 \%$ of the children came to the fourth, explanatory type of answers. One of the most frequent types of answers was an explanation that the brick was magical and the experimenter was a magician. Despite the answer being far from the truth, it nevertheless showed that a child exceeded the bounds of a visual side of the situation. It's amazing how such simple occurrences of a brick like its ability and inability to fall off the table make a child think of its miraculous nature. And there were the children who tried to analyze the situation. One of the boys said "At first I didn't see, and then at the last time I got it - I saw you tilt the box. Something rustled inside it I heard. It moves inside. The box is getting heavier."

5 -year-old children were similar in their answers and in their transition from type 1 answers to type 4 ones. However, the distribution according to types of answers obviously varies. There is an increase in the number of combined and explanatory answers.

6-years old children tend to give more explanatory answers and their explanations are much more diverse: "the brick is glued," "there's a magnet inside," "there's something in it." Answer distribution can be seen from Table 1. 


\begin{tabular}{c|c|c|c}
\hline & 4-year-old & 5-year-old & 6-year-old \\
\hline Persistent answer & $14 \%$ & $8 \%$ & - \\
Cyclic answer & $64 \%$ & $47 \%$ & $29 \%$ \\
Combined answer & $13 \%$ & $29 \%$ & $20 \%$ \\
Explanatory answer & $9 \%$ & $16 \%$ & $51 \%$ \\
\hline
\end{tabular}

Having analyzed all the answers in these experimental series we can fairly conclude as follows:

1. The experiment created a contradictory situation.

2. The contradictory situation brought about a dialectic task and initiated dialectic cognition. lows:

3. The general logic behind children's process of thinking was as fol-

a. The discrepancy between representational and perceptive images led to shaping of a complicated representational image of object having mutually exclusive properties.

b. Reflection upon a contradictory situation, namely the realization that it is impossible to make a correct prediction (this is an action of integration).

c. Formation of a dialectic task of mediation.

d. The mediation.

A dialectic task in this experiment was formed by the children at the last stage of transforming a contradictory situation.

To prove our understanding of dialectic cognition true, we have worked out a method of immediate introduction of a dialectic task. As long as most of 5-to-6-year-old children were able to solve the mediation task, we have chosen this mental action as the basis for our new experiment.

The children were given series of dialectic tasks on mediation, which where introduced verbally. For example, What can be at the same time: Alive and not alive? Black and white? Heavy and lightweight? The same and different?

We've noticed that these questions were quite easy for children and the nature of their answers indicated that children understood and accepted the presented dialectic tasks. 
The answers can be arranged in 4 groups:

1. Partial answers. A child selects an object that corresponds to only one of the two opposites. For example, "stone is heavy," "paper is white."

2. Transformational answers. A child states that one object can be in different states during different periods of time. For example, "sometimes a bag is heavy and sometimes it is lightweight."

3. Transitional answers. A child describes transition of an object from one state to different one. For example, "when you carry a stick, its light at first and then it becomes heavy."

4. Mediation. A child selects objects that possesses mutually exclusive properties and thus solves the task correctly.

Indeed, a doll in a game integrates two contradictory properties alive and not alive. Children treat a doll as a living thing - otherwise feeding it in a game would have no sense. And, at the same time, they know that it isn't alive and that's why children feed it with grass and pebbles. The game itself is possible only when the playing tools possess mutually exclusive properties. Such games help to develop dialectic cognition. Here is the distribution of children in accordance with their answers at solving dialectic task.

\section{Conclusion}

The results obtained from our experiments prove that preschool children possess a special type of cognition that operates the opposites. This allows them to make adequate predictions in contradictory situations. Therefore, dialectic cognition fundamentally determines prediction making process.

The most curious observation we made during all our experiments conducted between 1995 and 2005 was that indexes of dialectic cognition tended to decline dramatically when a child started to go to school. Only in individual cases can adults demonstrate the level of dialectic cognition comparable to the one of a senior preschooler. 


\section{References}

Davydov, V.V. (1972). Vidy obobŝseniâ v obučenii [Types of Generalization in Learning]. Moscow: Pedagogika.

Galperin, P.Ya. (1976). Vvedenie v psihologiû [Introduction to Psychology]. Moscow: MGU.

Galperin, P.Ya., \& Elkonin, D.B. (1967). K analizu teorii Ž. Piaže o razvitii detskogo myšleniâ [Analysis of J. Piaget's Theory on Development of Children's Thinking]. In J.H. Flavell, Genetičeskaâ psihologiâ Žana Piaže [The Developmental Psychology of Jean Piaget] (afterword, pp. 596-621). Moscow: Prosveŝenie.

Ilyenkov, E.V. (1974). Dialektičeskâ̂ logika [Dialectical Logic]. Moscow: Politizdat.

Leontiev, A.N. (1983). Izbrannye psihologičeskie proizvedeniâ. T. 2 [Collected Works in 2 volumes. Vol. 2]. Moscow: Pedagogika.

Maltsev, V.I. (1964). Očerk po dialektičeskoj logike [Essay on Dialectical Logic]. Moscow: MGU.

Veraksa, N.E. (1981). Osobennosti preobrazovaniâ protivorečivyh problemnyh situacij doškol'nikami [Transformations of Contradictory Situations by Preschool Children]. Voprosy psihologii, 3, 123-127.

Veraksa, N.E. (2007). Pensamiento Dialectico y Creatividad. Eclecta. Revista de Psicología General, 5 (11), 7-14.

Vygotsky, L.S. (1982). Sobranie sočinenij. T. 2 [Collection of Works in 6 volumes. Vol. 2]. Moscow: Pedagogika. 